OPEN ACCESS

Edited by:

May Lei Mei,

University of Otago, New Zealand

Reviewed by:

Ruoxi Dai,

The Second People's Hospital of

Hefei, China

Kai Chun Li,

University of Otago, New Zealand

${ }^{*}$ Correspondence: Riaan Mulder

rmulder@uwc.ac.za

Specialty section:

This article was submitted to Oral Hygiene and Oral Health Policy,

a section of the journal

Frontiers in Oral Health

Received: 02 October 2020

Accepted: 19 October 2020

Published: 17 November 2020

Citation:

Mulder R, Maboza E and Ahmed $R$ (2020) Streptococcus mutans Growth and Resultant Material Surface

Roughness on Modified Glass

lonomers.

Front. Oral. Health 1:613384 doi: 10.3389/froh.2020.613384

\section{Streptococcus mutans Growth and Resultant Material Surface Roughness on Modified Glass lonomers}

\author{
Riaan Mulder ${ }^{1 *}$, Ernest Maboza ${ }^{2}$ and Rukshana Ahmed ${ }^{1}$ \\ ${ }^{1}$ Restorative Dentistry, The University of the Western Cape, Cape Town, South Africa, ${ }^{2}$ Dental Research Laboratory, The \\ University of the Western Cape, Cape Town, South Africa
}

The present study investigate the optical density of Streptococcus mutans (S. mutans) at $450 \mathrm{~nm}(\mathrm{OD} 450 \mathrm{~nm})$ as well as the change in surface roughness of three commercially available chitosan- and nanodiamond-modified glass ionomers. The results indicated that the optical density of $S$. mutans OD450 nm decreased significantly $(p<0.0001)$ from $0 \mathrm{~h}$ through $2-4 \mathrm{~h}$ for each of the control materials. The lowest $S$. mutans OD450 nm was noted for Fuji IX followed by Ketac Universal. Riva Self Cure had the largest increase in the S. mutans OD450 nm. The control materials and their chitosan/nanodiamond modifications showed significant growth at $6 \mathrm{~h}$ compare to the preceding time periods of 2 and $4 \mathrm{~h}$. The materials Fuji IX, Fuji IX modified with 5\% Nanodiamonds, Fuji IX modified with 10\% Chitosan and Ketac Universal modified with 10\% Chitosan performed the best with regard to the bacterial reduction. Only the chitosan modifications showed an increase in the surface roughness after $24 \mathrm{~h}$ of exposure to the $S$. mutans. The chitosan and the nanodiamond modifications provided the best disruption of the $S$. mutans biofilm formation.

Keywords: antimicrobial effect, chitosan, glass ionomer, nanodiamond, Streptococcus mutans, surface roughness

\section{INTRODUCTION}

Streptococcus mutans (S. mutans) has been identified as one of the main role players in the development of dental caries [1]. S. mutans form part of the phylogenetic tree of 34 species of Streptococcus species that have been classified into five phylogenic groups per viridians [2]. S. mutans has been presented to be one of the most virulent bacterial species in the caries process $[3,4]$ and has been implicated in the progression of dental caries $[1,5,6]$. The metabolism of carbohydrates [7] by $S$. mutans results in its adherence to tooth structure and subsequent high aciduricity $[8]$ and acidogenecity $[6,9,10]$. Plaque samples have been shown to contain high levels of L-lactic isomer that is the main acid produced by S. mutans [11]. Glass ionomer cements (GICs) has become an option as a restorative material for high caries risk patients, since they are known to have an inhibitory influence on S. mutans [12] and have been shown to reduce their acid production $[13,14]$.

Various antibacterial materials have been incorporated into GICs in order to increase their antibacterial activity. These included but not limited to benzalkonium chloride [15], cetrimide [16], cetylpyridinium chloride [16], chlorhexidene [17], zinc sulfate [18], and silver or zinc zeolites [19]. 
Ching et al. [20], completed a literature review of 22 studies on various modifications of GICs that enhance their antibacterial activity. Many of the studies reviewed did not demonstrate a significant improvement in the antibacterial properties [20]. The studies where the chitosan [21-23] was incorporated into the liquid component of the GIC in a 5 and $10 \%$ volume per volume percent $(\mathrm{v} / \mathrm{v} \%)$ in relation to the control material showed favorable results $[22,23]$.

There are however various factors that influence the interaction of the micro-organisms with tooth structure and the restorative materials. The bacterial adherence, colonization, and growth of bacteria on the restoration and tooth structure have been linked to the surface roughness. Bacterial colonization on surfaces with a surface roughness $(\mathrm{Ra})$ of more than $0.2 \mu \mathrm{m}$ has been detected to be significant [24]. High levels of S. mutans were detected in plaque from saliva and the surfaces of carious teeth as well as sound teeth [1]. The interaction of $S$. mutans with dental materials has been of importance for dental research. Although GICs have been identified to have antibacterial properties, a bacterial biofilm can form on the surface of GICs [25]. The modification of GICs with chitosan- and nanodiamond particles in the powder of the GICs has never been assessed. This study therefore investigated the changes in the $S$. mutans OD450 nm as well as the resultant surface roughness of the chitosan- and nanodiamond-modified GICs.

The aims of the study were to investigate the change in surface roughness before and after 24 -h exposure, as well as the change in the OD450 nm of the $S$. mutans at different time intervals. The hypothesis was that chitosan- and nanodiamond-modified GICs would reduce the $S$. mutans OD $450 \mathrm{~nm}$ with no effect on the surface characteristics of the modified GICs.

\section{MATERIALS AND METHODS}

\section{Material Modification}

Three commercially available GICs namely FN: Fuji IX GP hand-mix (GC Corp, Tokyo, Japan; Batch: 1503231); KU: Ketac Universal hand-mix; (3M ESPE, Seefeld, Germany; Batch: 583514) and RSC: Riva Self Cure hand-mix (SDI Limited, Australia; Batch: 62657V) were used in this study. These GICs were modified in the powder phase with either 5 or $10 \%$ chitosan or nanodiamond particles.

The nanodiamond particles were commercially available and produced by detonation (PlasmaChem, Germany; item: PL$\mathrm{D}-\mathrm{G} 01)$. The nanodiamonds are produced by detonating $60 \%$ weight percentage TNT $\left(\mathrm{C}_{6} \mathrm{H}_{2}\left(\mathrm{NO}_{2}\right)_{3} \mathrm{CH}_{3}\right)$ and a $40 \%$ weight percentage of hexogen $\left(\mathrm{C}_{3} \mathrm{H}_{6} \mathrm{~N}_{6} \mathrm{O}_{6}\right)$ in a negative oxygen environment. The detonation occurs inside a metallic chamber with an atmosphere of $\mathrm{N}_{2}, \mathrm{CO}_{2}$ and liquid or solid water [26]. The average particle size is $4-6 \mathrm{~nm}$ and the particles generally present in non-fused diamond clusters. The carbon purity of $>98 \%$ has an enhanced stability ( $5 \mathrm{w} / \mathrm{v} \%)$ in a water suspension and carries a $-55 \pm 5 \mathrm{mV}$ Zeta potential.

The three GICs were modified in the powder phase per weight percentage $(\mathrm{w} / \mathrm{w} \%)$ by adding $5 \%$ or $10 \%$ of a commercially available chitosan particles (Merck, item 448877) or nanodiamond particles. The GICs modified with chitosan- and nanodiamond particles were produced by placing the GICs powder in an airtight high density polyethylene (HDPE) container. The containers were subsequently clamped in a beaker shaker for $2 \mathrm{~h}$ to ensure complete mixing of the two powders.

After modification with the chitosan- and nanodiamond particles, samples from the fifteen GICs were prepared in accordance with the manufacturers' powder/liquid ratios: (1) FN GIC powder [FN]; (2) FN GIC powder modified with 5-wt\% chitosan particles [FN5\%CH]; (3) FN10\%CH; (4) FN5\%ND; (5) FN10\%ND; (6) KU; (7) KU5\%CH; (8) KU10\%CH; (9) KU5\%ND; (10) KU10\%ND; (11) RSC; (12) RSC5\%CH; (13) RSC10\%CH; (14) RSC5\%ND; (15) RSC10\%ND.

\section{Sample Preparation}

The powder/liquid ratio prescribed by the manufacturer was followed and confirmed on a desktop analytical balance (Metler AE240 analytical balance, Columbus, OH, USA) by first dispensing the powder followed by the liquid. This ensured that the manufacturer's recommended powder/liquid ratio was maintained for all the GICs used in this study. Disc-shaped specimens of GIC were prepared $(7 \pm 0.1 \mathrm{~mm}$ diameter and $2 \pm 0.1 \mathrm{~mm}$ thickness) by packing the GICs into a Teflon split mold and covering it on both sides with polyester strips followed by a glass microscope slide and leaving it to set at room temperature $\left( \pm 23^{\circ} \mathrm{C}\right)$ for $1 \mathrm{~h}$. After setting, the polyester strips and microscope slides were removed and the specimens were stored for $24 \mathrm{~h}$ at $37^{\circ} \mathrm{C}$ and $100 \%$ humidity in a temperature controlled chamber. Samples were treated with wet siliconcarbide paper on both sides (1,200 grit sand paper as ISO99171:2007, as per the acid erosion test). Carlén et al. [27], illustrated that after polishing a GIC restoration, the protein/bacterial binding and the surface roughness did not change in relation to the GIC prior to polishing. Despite their result [27] this study design still retained a standard surface roughness $(\mathrm{Ra})$ and it was ensured during the surface preparation through the assessment of the surface roughness for each group of GICs to be within $\mathrm{Ra} \pm 2 \mu \mathrm{m}$.

\section{Surface Roughness}

Two surface roughness (Ra) measurements were recorded namely, before exposure to S. mutans [known as "Ra 0 (zero) h] and after exposure to $S$. mutans (known as Ra $24 \mathrm{~h}$ ). The operator was blinded to the GICs modification and material that was assessed. An independent researcher responsible for the blinding of the material samples assessed that all the samples per group complied with the $\mathrm{Ra} \pm 2 \mu \mathrm{m}$. The $\mathrm{Ra}$ of all the materials were measured with a Leeb surface roughness tester with a standard sensor (Model Leeb432, Chongqing Leeb Instrument co., Ltd.). The $\mathrm{Ra}$ tester has a wide measuring range between 0.005 and $16 \mu \mathrm{m}$ for surface roughness.

The testing parameters in this study were: surface roughness $(\mathrm{Ra})$, the filter option was adjusted to the Gauss setting, the assessment length $(\lambda c)$ at $0.8 \mathrm{~mm} \times n 5$ (assessment length $(\mathrm{Ln}=\mathrm{lr} \times n) ; \mathrm{Ln}=3.2 \mathrm{~mm})$. The standard stylus has a natural diamond at a $90^{\circ}$ cone angle with a $5 \mu \mathrm{m}$ tip radius. The stylus applied a force to the sample of $<4 \mathrm{mN}$. The traveling speed (Vt) 
for the above parameters was $0.135 \mathrm{~mm} / \mathrm{s}$ and the measurement accuracy was $\pm 10 \%$.

Two parallel lines were recorded $2 \mathrm{~mm}$ apart with two lines perpendicular to that $(n=4)$ per side of each sample. The aforementioned measurements for both sides of the sample ( $n=8$ ) were therefore recorded and the average of the eight measurements was used as the mean Ra per specimen for time period $\mathrm{Ra} 0 \mathrm{~h}$. The GICs samples were re-assessed after $24 \mathrm{~h}$ subsequent to the 24-h exposure to the tryptic soy broth containing $S$. mutans (TSB/S. mutans broth) at Ra $24 \mathrm{~h}$. Subsequent to removing the GICs samples from the $\mathrm{TSB} / S$. mutans growth medium, a 10 -s vortex in $5 \mathrm{~mL}$ deionized water was completed to remove any S. mutans biofilm and bacteria from the surface of the GICs. The aforementioned samples $(n=8)$ for Ra readings were then repeated. The mean percentage difference was calculated for the five samples per GICs group in relation to the $\mathrm{Ra} 0 \mathrm{~h}$ value. A positive percentage value indicated an increase in $\mathrm{Ra}$ from $\mathrm{Ra} 0 \mathrm{~h}$ to $\mathrm{Ra} 24 \mathrm{~h}$.

\section{Sterilization}

Sterilization of the GICs samples were completed after the first surface roughness readings ( $\mathrm{Ra} 0 \mathrm{~h}$ ) was completed. The GICs specimens and the $5 \mathrm{~mL}$ cryotubes were sterilized with ethylene oxide gas (Steri-Vac 4XL gas sterilizer, Model 400DGP, $3 \mathrm{M}$, St Paul, MN, USA). The ethylene oxide gas was used, since the rise in temperature to $120^{\circ} \mathrm{C}$ in the steam autoclave could alter the surface due to moisture absorption and the high temperature, causing surface cracks in the GICs that was not part of normal maturation. The development of cracks would alter the surface roughness.

\section{Reconstitution of S. mutans}

S. mutans bacteria (ATCC 25175) was reconstituted in brain heart infusion (BHI broth) for $24 \mathrm{~h}$ at $37^{\circ} \mathrm{C}$ and streaked on a contact plate (TSA LTHth-ICR, Merck Life Science GmbH; Eppelheim; Germany; Batch 140477) in order to isolate a single S. mutans colony.

The single S. mutans colony (ATCC 25175) taken from the agar plate was grown overnight at $37^{\circ} \mathrm{C}$ under $5 \% \mathrm{CO}_{2}$ conditions in a BHI broth. The overnight culture was added in $5 \mu \mathrm{L}$ at a time to the sterile phosphate buffered saline (PBS). The McFarland 0.5 was established and assessed with the DensiCHECK plus measuring device at a $580 \mathrm{~nm}$ wavelength (BioMerieux Inc, Hazelwood, Missouri, USA). The McFarland 0.5 was equivalent to a concentration of $1.5 \times 10^{8} \mathrm{~S}$. mutans cells $/ \mathrm{mL}$ in the PBS solution. One thousand milliliters of tryptic soy broth (TSB) was manufactured using $30 \mathrm{~g}$ of TSB (TSB CM0129; Oxoid Ltd.; Basingstoke; Hampshire; UK) mixed with $1,000 \mathrm{~mL}$ of de-ionized water and sterilized in an autoclave at $121^{\circ} \mathrm{C}$ for $15 \mathrm{~min}$. After the broth had cooled to $23^{\circ} \mathrm{C}, 50 \mu \mathrm{L}$ of the McFarland standard 0.5 S. mutans/PBS suspension $\left(1.5 \times 10^{8}\right.$ S. mutans cells $/ \mathrm{mL}$ in PBS) was added to $5 \mathrm{~mL}$ of TSB in the sterile cryotubes (TSB/S. mutans). The inoculated $5 \mathrm{~mL} \mathrm{TSB} / \mathrm{S}$. mutans and the five GIC samples per material were placed in an orbital shaking incubator (MRC, Holon, Israel) at $37^{\circ} \mathrm{C}$ with a speed of 120 rotations per hour. The $S$. mutans control was sterile cryotubes inoculated with the same $S$. mutans, but no GICs were added to these cryotubes. The $S$. mutans control would provide the growth pattern in order to evaluate the effect of the various GICs investigated in this study.

\section{Colorimetric Assay (XTT Based) of Cell Proliferation and Viability}

The changes in the $S$. mutans optical density measured at $450 \mathrm{~nm}$ (OD450 nm) of $S$. mutans were evaluated at $0,2,4,6$, and $24 \mathrm{~h}$. The $5 \mathrm{~mL}$ cryotubes was tipped twice at $180^{\circ}$ and $300 \mu \mathrm{L}$ from the $5 \mathrm{~mL}$ cryotubes $\mathrm{TSB} / \mathrm{S}$. mutans bottle was equally divided between three wells on a 96 -well plate at $37^{\circ} \mathrm{C}$ [28]. For the XTT analysis, each well of the 96-well plate contained $100 \mu \mathrm{L}$ $\mathrm{TSB} / S$. mutans and $50 \mu \mathrm{L}$ of a XTT Cell Proliferation kit II (Roche Diagnostics GmbH, Mannheim, Germany). The XTT labeling reagent and coupling agent were mixed in accordance with the manufacturers' instructions (Roche Diagnostics $\mathrm{GmbH}$, Mannheim, Germany). The spectrophotometer measurements were taken after $4 \mathrm{~h}$ of incubation at $450 \mathrm{~nm}$ (Smart Microplate Reader, Model SMR16.1. USCN life science kit Inc, Wahan, China). At optical density of $450 \mathrm{~nm}$, the mitochondrial activity was determined with the aid of formazan dye.

\section{Statistical Analysis}

The statistical analysis for the S. mutans bacterial OD450 nm was completed in two stages. Stage 1: The change in the bacterial OD450 $\mathrm{nm}$ for 2, 4, 6, and $24 \mathrm{~h}$ was assessed against the $0 \mathrm{~h} \mathrm{~S}$. mutans OD450 $\mathrm{nm}$ within the three materials (FN, $\mathrm{KU}$ and RSC) and then with their respective chitosan and nanodiamond modifications. The one way ANOVA with linear mixed modeling was completed. The data were considered to be longitudinal for which the linear mixed effects models have been developed (Modern Applied Statistics with S, by W.N. Venables and B.D. Ripley).

Stage 2: One-way ANOVA was used with the $p$-value corresponding to the F-statistic of one-way ANOVA $p<0.05$. This suggests that one or more treatments for $S$. mutans OD450 nm were significantly different between the control and the three materials (FN, KU, and RSC) and their chitosan and nanodiamond modifications. The post-hoc Holm-Bonferroni formula for the first-ranked $p$-value was used to determine the true significance for $0,2,4,6$, and $24 \mathrm{~h}$ in relation to the control S. mutans OD450 $\mathrm{nm}$ for the same time periods.

The change in surface roughness between 0 and $24 \mathrm{~h}$ were calculated as a percentage by using the following formula: $[(100 /$ Ra 0 h $) \times(\operatorname{Ra} 24 h)]-[100]$.

\section{RESULTS}

\section{Surface Roughness Change (Ra)}

Figure 1 illustrates the difference of the surface roughness between the start of the experiment $(0 \mathrm{~h})$ and the end of the study $(24 \mathrm{~h})$. A positive percentage change of the surface roughness from 0 to $24 \mathrm{~h}$ represents an increase in surface roughness. Table 1 indicates the precise surface roughness values as recorded for each material at 0 and $24 \mathrm{~h}$ with significant differences presented by a $p<0.05$. 


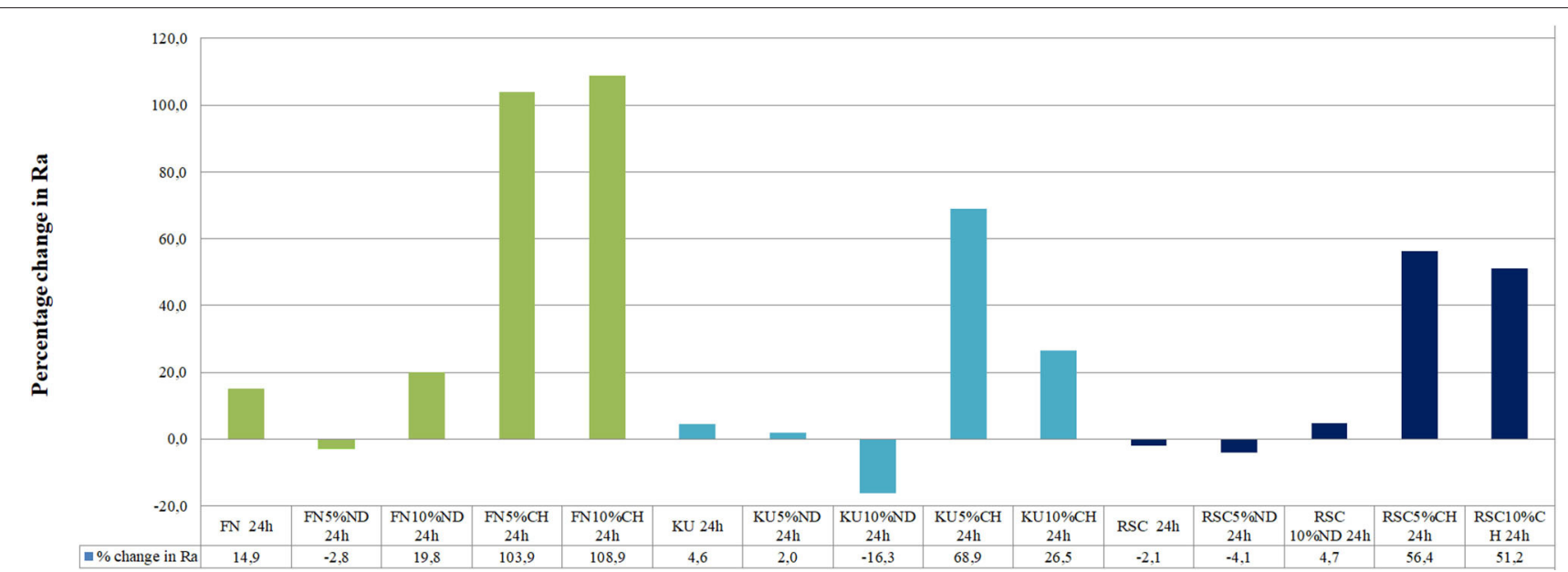

FIGURE 1 | Percentage of surface roughness change of the GICs surfaces from 0 to $24 \mathrm{~h}$.

TABLE 1 | Change in surface roughness values $(\mu \mathrm{m})$ from 0 to $24 \mathrm{~h}$ for each material.

\begin{tabular}{|c|c|c|c|c|c|}
\hline & FN & FN5\%ND & FN10\%ND & FN5\%CH & FN10\%CH \\
\hline $\mathrm{RaO} \mathrm{h}$ & 0.971 & 1.371 & 0.990 & 1.023 & 1.650 \\
\hline \multirow[t]{2}{*}{ Ra $24 \mathrm{~h}$} & 1.116 & 1.333 & 1.187 & $2.085^{\wedge}$ & $3.447^{\wedge}$ \\
\hline & KU & KU5\%ND & KU10\%ND & KU5\%CH & $\mathrm{KU} 10 \% \mathrm{CH}$ \\
\hline $\mathrm{RaOH}$ & 0.833 & 0.736 & 0.924 & 1.196 & 1.581 \\
\hline \multirow[t]{2}{*}{ Ra 24 h } & 0.871 & 0.751 & 0.774 & $2.021^{\wedge}$ & $2^{\wedge}$ \\
\hline & RSC & RSC5\%ND & RSC10\%ND & $\mathrm{RSC} 5 \% \mathrm{CH}$ & $\mathrm{RSC} 10 \% \mathrm{CH}$ \\
\hline $\mathrm{RaOH}$ & 1.366 & 1.163 & 1.244 & 1.617 & 1.797 \\
\hline Ra 24 h & 1.338 & 1.115 & 1.301 & $2.528^{\wedge}$ & $2.716^{\wedge}$ \\
\hline
\end{tabular}

$\wedge$ indicates significant change $p<0.05$ within the respective material group.

Comparison of the optical density (OD450 nm) absorbance values from the XTT test is indicated in Table 2. The significant differences between the material and the S. mutans control in Table 2 are indicated per time period. The ANOVA of the OD450 nm achieved in the XTT test of $S$. mutans identified significant differences between the three control materials (FN; KU; RSC: $p<0.0001)$. This difference indicates significant differences between the amounts of viable streptococci at $24 \mathrm{~h}$ for the three control materials. The lowest $S$. mutans OD450 nm was noted for FN (0.783) followed by KU (0.927). RSC (1.056) had the largest S. mutans OD450 nm.

\section{S. mutans and the Control Materials}

Table 2 illustrates the $S$. mutans growth incubated with the GIC material over time. The $S$. mutans OD450 nm decreased significantly $(p<0.0001)$ from $0 \mathrm{~h}$ through $2-4 \mathrm{~h}$ for each material. At $6 \mathrm{~h}$, the $S$. mutans OD $450 \mathrm{~nm}$ increased when compared to 0,2 , and $4 \mathrm{~h}$. There were no significant differences
TABLE 2 | Comparison of the mean OD450 nm of S. mutans control and the dental materials per time period.

\begin{tabular}{lccccc}
\hline Material & \multicolumn{5}{c}{ Hours } \\
\cline { 2 - 6 } & $\mathbf{0}$ & $\mathbf{2}$ & $\mathbf{4}$ & $\mathbf{6}$ & $\mathbf{2 4}$ \\
\hline S. mutans control & 0.717 & 0.607 & 0.601 & 0.680 & 0.944 \\
FN & 0.726 & 0.563 & 0.571 & 0.658 & $0.783^{\star}$ \\
FN5\%CH & $0.593^{\star}$ & 0.555 & 0.542 & 0.653 & $0.762^{\star}$ \\
FN10\%CH & 0.635 & 0.553 & 0.552 & 0.625 & $0.689^{\star}$ \\
FN5\%ND & 0.623 & 0.567 & 0.528 & 0.629 & $0.759^{\star}$ \\
FN10\%ND & $0.686^{\wedge}$ & 0.711 & 0.670 & 0.753 & $0.831^{\star}$ \\
KU & $0.620^{\star}$ & 0.570 & 0.588 & 0.608 & 0.927 \\
KU 5\%CH & $0.616^{\star}$ & 0.548 & 0.569 & 0.617 & 0.903 \\
KU 10\%CH & $0.597^{\star}$ & $0.531 \wedge$ & 0.611 & 0.678 & $0.842^{\star}$ \\
KU 5\%ND & $0.635^{\star}$ & 0.566 & 0.565 & $0.577^{\star}$ & 0.930 \\
KU 10\%ND & $0.570^{\wedge}$ & 0.539 & 0.536 & 0.650 & 0.906 \\
RSC & $0.587^{\star}$ & 0.536 & $0.515^{\wedge}$ & 0.618 & 1.056 \\
RSC 5\%CH & $0.586^{\star}$ & 0.535 & 0.552 & 0.630 & 1.045 \\
RSC 10\%CH & $0.558^{\star}$ & 0.525 & 0.547 & 0.633 & 1.021 \\
RSC 5\%ND & $0.533^{\star}$ & 0.543 & 0.557 & $0.598^{\wedge}$ & 0.973 \\
RSC 10\%ND & 0.668 & 0.592 & $0.516^{\wedge}$ & 0.635 & 1.081 \\
\hline
\end{tabular}

*indicates significant difference $(p<0.01)$ with the $S$. mutans control for the same time period.

$\wedge$ indicates significant difference $(p<0.05)$ with the $S$. mutans control for the same time period.

in the OD450 $\mathrm{nm}$ at any time period $(0,2,4$, and $6 \mathrm{~h})$ between the three control GIC materials with $p=0.9969$. At $24 \mathrm{~h}$ there were significant differences between all three control materials $(p$ $<0.0001)$. The lowest $S$. mutans OD450 nm was noted for FN followed by KU. RSC had the largest $S$. mutans OD450 nm.

\section{Nanodiamond Modification of GICs}

The ANOVA of the OD450 $\mathrm{nm}$ achieved in the XTT test of the control material compared to its respective nanodiamond 
modification identified no significant differences $(p>0.05)$. There were no significant differences in the S. mutans OD450 nm at any time period $(0,2,4,6$, and $24 \mathrm{~h})$ between the various comparison pairs: FN vs. FN5\%ND; FN vs. FN10\%ND; KU vs. KU5\%ND; KU vs. KU10\%ND; RSC vs. RSC5\%ND; RSC vs. RSC 10\%ND.

\section{Chitosan Modification of GICs}

The ANOVA of the OD450 $\mathrm{nm}$ achieved in the XTT test of the control material compared to its respective chitosan modification identified no significant differences $(p>0.05)$. There were no significant differences in the $S$. mutans OD450 $\mathrm{nm}$ at any time period $(0,2,4,6$, and $24 \mathrm{~h})$ between the various comparison pairs: $\mathrm{FN}$ vs. $\mathrm{FN} 5 \% \mathrm{CH}$; $\mathrm{FN}$ vs. $\mathrm{FN} 10 \% \mathrm{CH}$; $\mathrm{KU}$ vs. $\mathrm{KU} 5 \% \mathrm{CH}$; $\mathrm{KU}$ vs. $\mathrm{KU} 10 \% \mathrm{CH}$; RSC vs. RSC5\%CH; RSC vs. RSC10\%CH.

\section{Nanodiamond vs. Chitosan Modification of GICs}

The ANOVA of the OD450 $\mathrm{nm}$ achieved in the XTT test of the GIC modified with nanodiamond particles vs. chitosan, identified no significant differences $(p>0.05)$.

\section{DISCUSSION}

The hypothesis was not accepted that chitosan-modified GICs would reduce the S. mutans OD450 $\mathrm{nm}$ at 24 -h for KU and RSC with no significant effect on the surface characteristics of these two chitosan- and nanodiamond modified GICs. It was however accepted for FN GICs modified with nanodiamonds.

Nanodiamonds combined with GICs posed the potential for enhancing the antibacterial activities of GICs. Table 2 illustrates that all the assessed commercial GICs (FN, KU, and RSC) showed a reduction in the $S$. mutans $\mathrm{OD} 450 \mathrm{~nm}$ in relation to the control bacteria. Although it was not significantly reduced for FN when compared to the control for 2,4 , and $6 \mathrm{~h}$, there was a significant reduction at the 24-h growth period. The growth period at 24$\mathrm{h}$ is important, since this plaque biofilm will cause an increased risk for caries. This was the general trend for the chitosan and nanodiamond modifications as well. KU and RSC showed similar trends with a significant reduction in S. mutans OD $450 \mathrm{~nm}$ for 0 and $4 \mathrm{~h}$ compared to the control bacteria. This study therefore illustrates that when the GICs are exposed to the $S$. mutans for 2,4 , and $6 \mathrm{~h}$, there was a decrease in the $S$. mutans OD450 $\mathrm{nm}$ in relation to the control bacteria. The immediate short term effect of the nanodiamonds are attributed to the carboxylic groups that are among the most common and abundant functional groups [29]. The carboxylic groups present on the nanodiamond surface and participate in ion exchange during the GICs acidbase reactions. The ion exchange occur specifically with $\mathrm{Al}^{3+}$ and $\mathrm{Sr}^{2+}$ to form various metal salts which can be released upon hydrolysis [30] and provide antibacterial properties to the GICs.

The colonization of plaque in the oral cavity and on various surfaces is complicated and occur in phases. Firstly, the various components of saliva, crevicular fluid, and colonizing bacteria play a role in pellicle formation $[31,32]$. The bacterial adherence to the inhabiting environment is essential to their survival in the oral cavity [33]. Studies on the bacterial adherence to
GICs and the subsequent biofilm formation on the surface have shown that GICs do influence the bacterial adherence as well as the biofilm formation [13,34]. The addition of the modifications shown to be effective to reduce the growth in the initial time periods. The biofilm comprises of the initial adsorption of glucan-binding proteins produced from the saliva [31] by $S$. mutans [35] and pioneer bacterial colonies within the pellicle. S. mutans synthesize an adhesive glycan from sucrose [36] and in combination with the van der Waals electrostatic forces, create a reversible adherence to teeth. As the various microbes of especially $S$. sangius and S. mutans anchor to the pellicle, the plaque becomes visible after $12-24 \mathrm{~h}$. The extracellular polysaccharides (EPSs), glucosyltransferases (GTFs) [37] and the various proteins produced by bacteria [38] can all be vulnerable to the influence of the nanodiamond particles incorporated into the GICs. FN has been extensively used for in vitro studies on various aspects of research on its properties and clinical success [39] and is therefore an ideal material to have as a control material. The success of the FN material modified with nanodiamonds to reduce the bacterial growth without significant effects on the Ra illustrate the versatility of the material to be modified with nanodiamonds.

At 0 and $24 \mathrm{~h}$, the $S$. mutans $\mathrm{OD} 450 \mathrm{~nm}$ were variable between the different chitosan and nanodiamond modifications in relation to the control. With significant differences $(p<$ 0.0001 ) noted between the three control materials at $24 \mathrm{~h}$, it became clear from Figure 2 that the S. mutans OD $450 \mathrm{~nm}$ of FN (0.783) (Figure 2A), KU (0.927) (Figure 2B) and RSC (1.056) (Figure 2C) differed. The arrows indicate S. mutans formed biofilms with various thicknesses. The S. mutans for the material samples of FN and $\mathrm{KU}$ were smaller and more individually spread, with the filler particles of the GICs still visible. For RSC, the biofilm ranged from transparent biofilm to very thick biofilm coverage of the filler particles and matrix of the GICs with many quorum forming $S$. mutans. Figure 2 correlates well with the result at $24 \mathrm{~h}$ where the biofilm that formed was the thickest and best developed for RSC followed by KU and then FN with the thinnest biofilm.

The antibacterial effect of the nanodiamond particles originate from the reduction in ATP production of gram-negative Escherichia coli to $<10 \%$. When compared to the control, this was achieved within 15 min with nanodiamond particles in a concentration of 50 and $500 \mathrm{mg} / \mathrm{L}$. Similar results were noted with the gram-positive bacterium of Bacillus subtilis [40]. In the present study, a similar trend was observed with the nanodiamond modifications of FN, KU and RSC where many of the GICs modifications had a significant reduction at $0 \mathrm{~h}$ (after $20 \mathrm{~min}$ of exposure to $S$. mutans) compared to the $S$. mutans control. Wehling et al. [40], further identified that nanodiamond particles with $E$. coli at a non-lethal dose $(0.5 \mathrm{mg} / \mathrm{L})$ were phagocytosed by the bacterium. Wehling et al. [40], concluded that the antibacterial property of these nanodiamonds (PL-DG01) was not only due to the surface functional groups of the nanodiamonds, but also to the change in the Zeta potential. The loss of the surface reactive functional groups resulted in the reduction of the negative Zeta potential to become more positive. The acid anhydrate functional group was established 
A

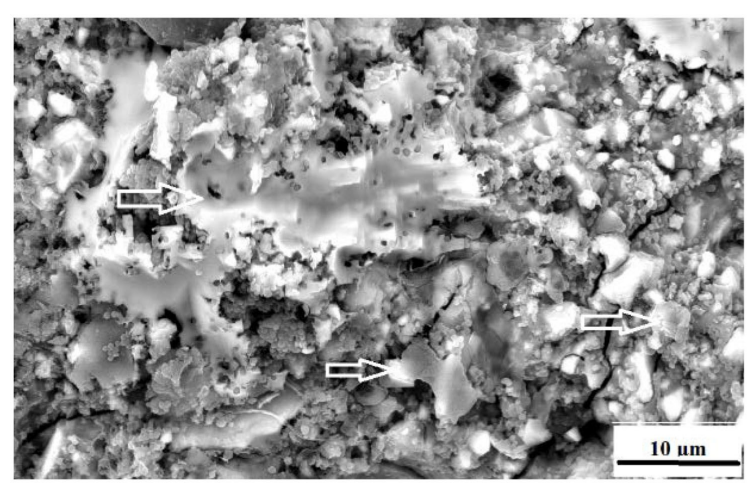

B

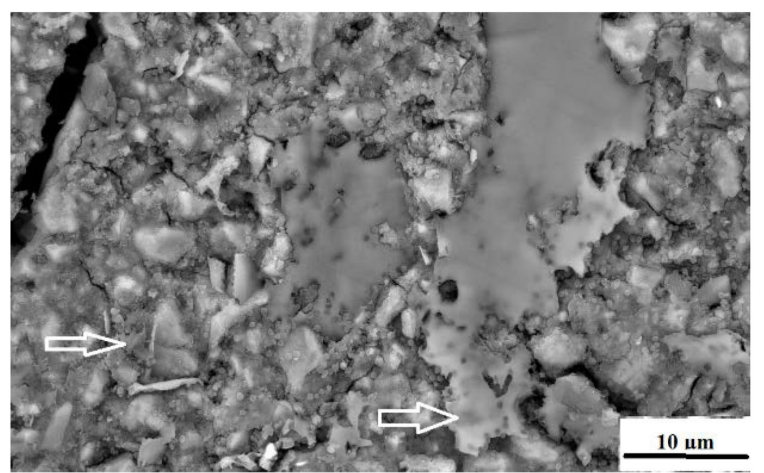

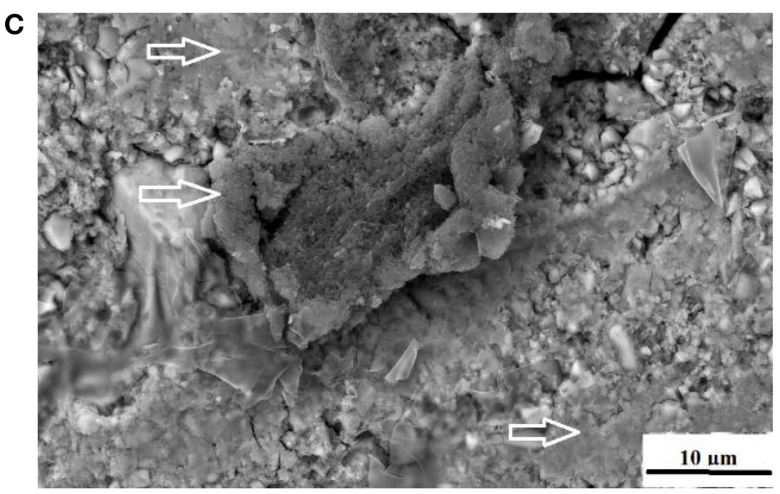

FIGURE 2 | The white arrows indicate the S. mutans biofilm on the surface of the control GICs. (A) FN present with the thinnest biofilm; (B) KU present with thicker biofilm than FN; (C) RSC present with a biofilm ranging from transparent to very thick.

to be the distinguishing antibacterial group of the nanodiamond particle $[40,41]$. In the nanodiamond-modified GICs used in this in vitro study, non-covalent interactions occurred between the nanodiamond particles, the ions of the GIC and the polyacrylic liquid [42]. This type of non-covalent interaction would therefore include ionic interactions, hydrogen bonding and dipoledipole bonding to the nanodiamond particles' (PL-D-G01) terminated carboxyl groups and the other oxygen-containing groups $[40,43]$.

The nanodiamond particles used in this in vitro study were supplied by the manufacturer as non-clustered. Unfortunately it was noted that, the clustering (or rather agglomeration) of the nanodiamond particles did however occur while they were stored in their packaging due to various cohesive and adhesive forces between the nanodiamond particles [44]. This is an unavoidable property of nanodiamonds. These clusters form due to capillary forces pulling the individual nanoparticles together during the drying of the nanodiamonds (for storage) at the time of manufacture [43]. This has physical implications for the incorporation of nanodiamond particles into GICs powder. The advantage of the GICs hand-mixing process was that the agglomerated nanodiamond particles seemed to become smaller during mixing. Upon visual inspection the material seem homogeneously mixed with seemingly small clusters of agglomerated nanodiamond particles noted. The spatulation process separated many of them into micro-sized agglomerated clusters, but the nanoparticle size was not easily achieved the higher the percentage of nanodiamonds became.

An advantage of nanodiamonds is the large surface area due to the nano size of the particles. When the nanoparticles agglomerate during the drying process to form a larger "microdiamond agglomerated particle," there are fewer functional groups around the circumference of the particle that can interact with the ions from the GICs and the forming matrix. The inner particle in the cluster remain shielded from interaction during the acid base reaction. The interaction of these agglomerated nanodiamond particles with the substrate (e.g., GICs), might not be suitable if the powder and liquid do not integrate completely during the mixing process. This integration of the liquid with the nanodiamonds occurs to a point, but the agglomerated nanodiamond particle interaction with the GICs is based on the wetting ability of the liquid to the nanodiamond particles and the rate of polyacrylic acid absorption during mixing. This resulted in the need to assess the surface roughness (Ra) after $S$. mutans exposure. The interaction of the $S$. mutans with the modified GICs material surface was essential to assess the interaction of the incorporated particle for long term success of the modified GICs. Figure 3 illustrates the interaction at the edge of an agglomerated nanodiamond particle (gray surface on the left) to the GIC matrix (right) with the red/white arrow 


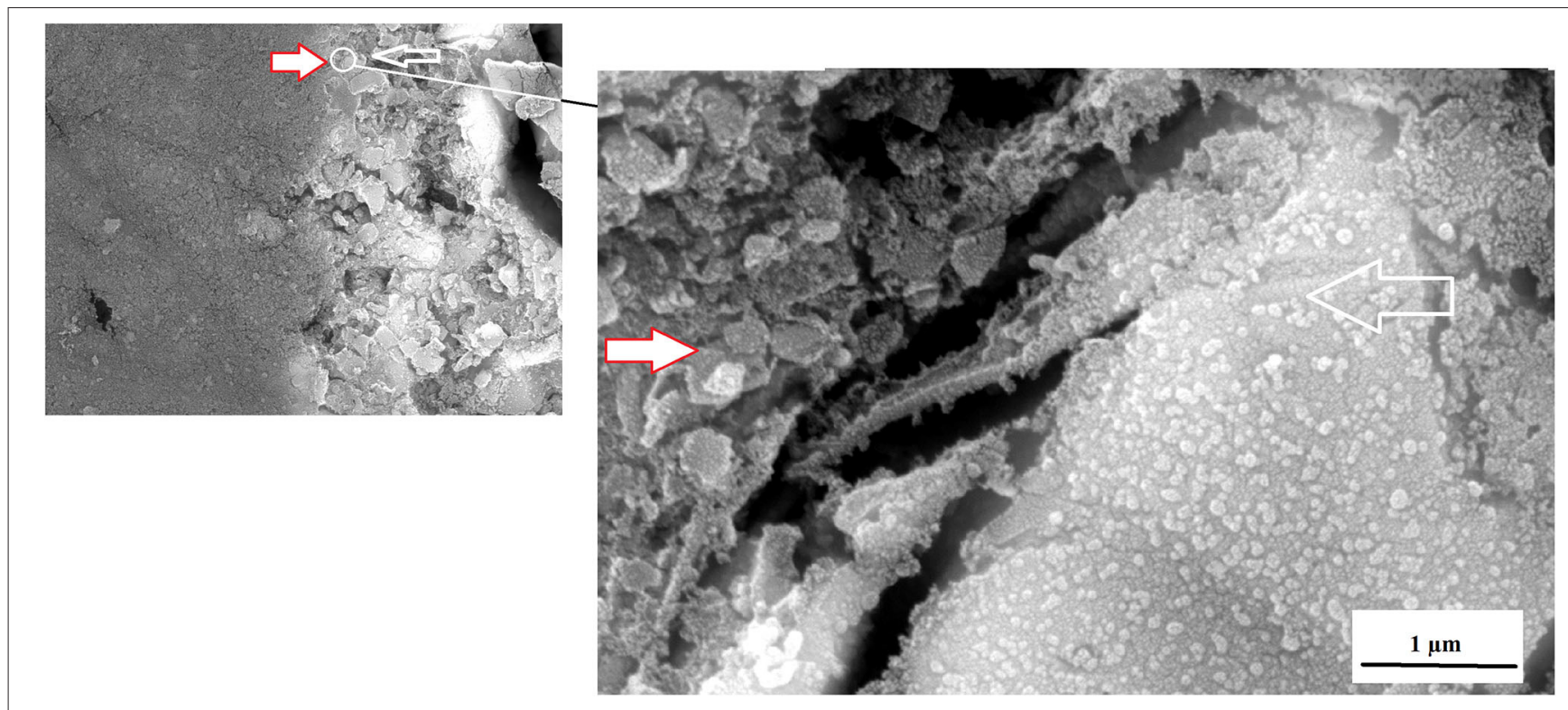

FIGURE 3 | KU5\%ND nanodiamond agglomerate (red/white arrow) and the GIC matrix (white arrow).

indicating the nanodiamond. In Figure 3, it can be clearly seen that the edge of the agglomerated nanodiamond particle was bound to the GIC matrix. The S. mutans at the white arrow is clearly visible on the GIC filler particle with only a few individual $S$. mutans seen on the nanodiamond agglomerated particle, indicated by the red/white arrow (Figure 3).

Surface irregularities like cracks and pits on teeth are the ideal area for early microbial adherence and subsequent plaque formation on the enamel [45]. It has been well documented that the increase in surface roughness of the material result in a deterioration of the material surface $[46,47]$. The integrity of the nanodiamond agglomerated particle is dependent upon: (1) the size of the agglomerated nanodiamond particles, (2) the volume of absorbed polyacrylic acid into the agglomerated nanodiamond particle, (3) interaction with the GIC matrix, and (4) the strength of the forces keeping these agglomerated nanodiamond particles together (that were not hydrated with polyacrylic acid). Based on these aforementioned factors the development of voids of various sizes in the center of the nanodiamond-agglomerated particles will occur as the center [29] nanodiamond particles are lost in Figure 4, exposing the GIC surface (indicated by the black arrow). When the nanodiamond particles are lost from the center of the agglomerated nanodiamond particle (indicated by the white arrow), since they are loosely bound with van der Waals forces if the liquid from the GIC does not penetrate into the agglomerated particle. The loss of the nanodiamondagglomerated particles from the surface of the GIC (indicated by the black arrow) additionally confirmed that the outer margin of the smaller nanodiamond-agglomerated particles (that were moistened by the matrix and the polyacrylic acid) are well-fused with the matrix of the GIC (Figure 4).

The surface roughness $(\mathrm{Ra})$ from 0 to $24 \mathrm{~h}$ presented with the lowest surface roughness for the $5 \% \mathrm{ND}$ modification of $\mathrm{FN}, \mathrm{KU}$ and RSC compared to their respective $10 \% \mathrm{ND}$ modifications and all the chitosan modifications (Table 1). Although the chitosan modifications had significant increases in the surface roughness, it was attributed to the swelling effect and the interaction of $S$. mutans with the chitosan particles. Therefore, the approach where the chitosan is incorporated into the liquid form remain the most optimal modification for GICs [21-23]. The 24$\mathrm{h}$ exposure of the $S$. mutans to the control materials and their respective nanodiamond modifications did not significantly change their surface roughness (Figure 1). The original particle size of the chitosan material as received from the manufacturer clearly influenced the surface roughness, due to: (1) the larger chitosan particle (Figures 5A,B) which already increase the surface roughness at $0 \mathrm{~h}$ compared to the nanodiamond-modified GICs with the smaller agglomerated particles (Figure 1). (2) Their irregular shape (Figures 5B,C). (3) The difference in the chitosan particle distribution [48] within the GICs material (Figures 5C,D). (4) The increase in volume noted of the chitosan as it is exposed to moisture. (5) Non-fusion of the chitosan particle with the GIC (Figure 5D).

The antibacterial properties of chitosan was first noted and applied as a wound dressing for skin and other trauma in 2005 according to the Food and Drug Administration (FDA) registration (Hemcon bandage, Portland, Oregan, USA). Colonization of the chitosan with $S$. mutans is expected to some extent considering that an in vivo study has shown that $S$. mutans colonization for various restoration margins is always present, even in different patients [1]. The surfaces of crowns, amalgams and composites have shown consistent $S$. mutans colonization, although the amount of colonization had great variability when the OD $450 \mathrm{~nm}$ between restorations and the OD450 nm of saliva from the same patients were compared [49]. The chitosan materials seem to have fewer singular S. mutans as 


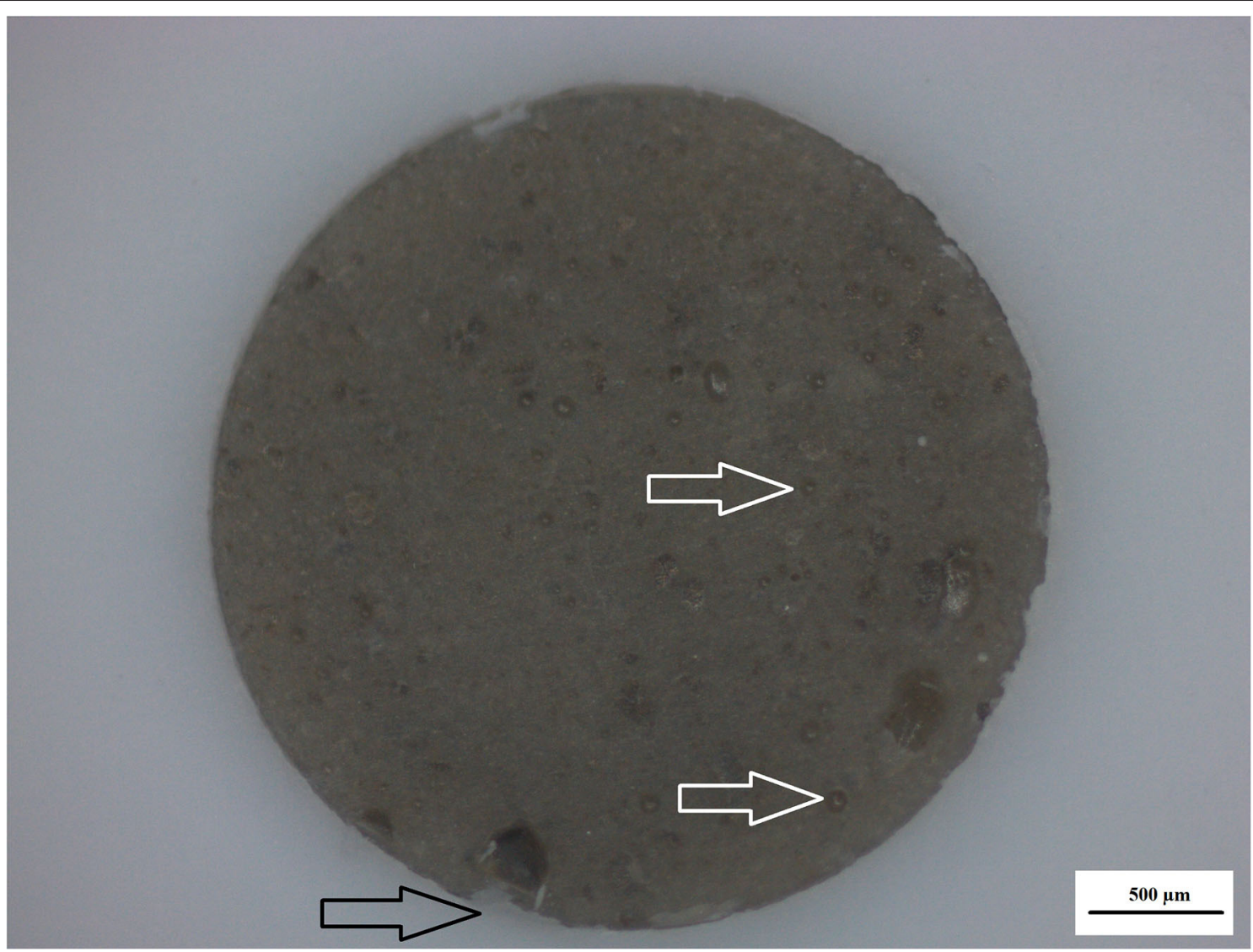

FIGURE 4 | Nanodiamond modified GIC. Nanodiamond cluster lost (black arrow) and nanodiamond particles lost from center of cluster (white arrows).

illustrated by the white arrows highlighting the quorum function in the thick biofilm growth from the chitosan particle (Figure 6).

The individual, quorum forming and various appearances of the biofilm produced by the S. mutans in this study appear different on each GICs surface. This could be due to the fact that chitosan was derived from aminopolysaccharide copolymers of glucosamine and $\mathrm{N}$-acetylglucosamine. The chitosan particles contain primary amino groups in the main backbone of the molecule, resulting in the positive charge of the surface [50]. S. mutans has a negative charge and is therefore attracted to the surface of the chitosan particle. Further to the amino acids (acetamino acetamide $\left(\mathrm{CH}_{3} \mathrm{CONH}_{2}\right)$ [51], there are hydroxyl groups at the $\mathrm{C} 2$ positions of the glucose ring as well as $\mathrm{D}$ glucosamine that are able to biodegrade and interact with the biological surfaces [50]. Chitosan particles contain many active hydroxyl groups and amino acids that have been attributed to its ability to scavenge hydroxide radicals [52]. This strong scavenging ability of the hydroxyl radicals is important, since it is known to damage amino acids, DNA and proteins [53]. Upon contact with the positively charged chitosan and the negatively charged $S$. mutans, the bacterial cell wall and the protonated ammonia $\left(\mathrm{NH}^{3+}\right)$ from chitosan will compete for the calcium $\left(\mathrm{Ca}^{2+}\right)$. The calcium usually stabilizes the bacterial cell wall and with its reduction, two interferences can occur as cited by a review article by Goy et al. [54]. These include: (1) bacterial cell wall membrane permeability change causing an inhibition of $S$. mutans growth and (2) hydrolysis of the cell wall leading to the leakage of potassium, proteins, nucleic acids, glucose, and lactate dehydrogenase from S. mutans [54]. This explains the varied appearance between FN5\%ND (Figure 7A) and FN10\%CH (Figure 7B).

The chitosan particles used in the present in vitro study was the $75-85 \%$ deacetylated particles. In studies $[55,56]$, the chitosan particles showed anti-bacterial properties, but were dissolved in acetic acid whereas in the present in vitro study the chitosan particles were used in the supplied particle form. The only protonation that can occur on chitosan is therefore during the mixing stage as well as the acid-base reaction with the polyacrylic liquid. Even with the ion release from GICs, the adhesion of the $S$. mutans did not seem to be influenced when compared to the other materials [57]. This led the research group of Eick et al. [57], to question the effectiveness of GICs against $S$. mutans. It was well-accepted that fluoride release could influence the S. mutans [58], but Montanaro et al. [59], rejected this due to the lack of change in the adhesion of $S$. mutans in relation to other materials tested. To this effect, the adherence of $S$. mutans to the various aspects of the KU (Figure 8A) and RSC (Figure 9A) are illustrated where the 
A

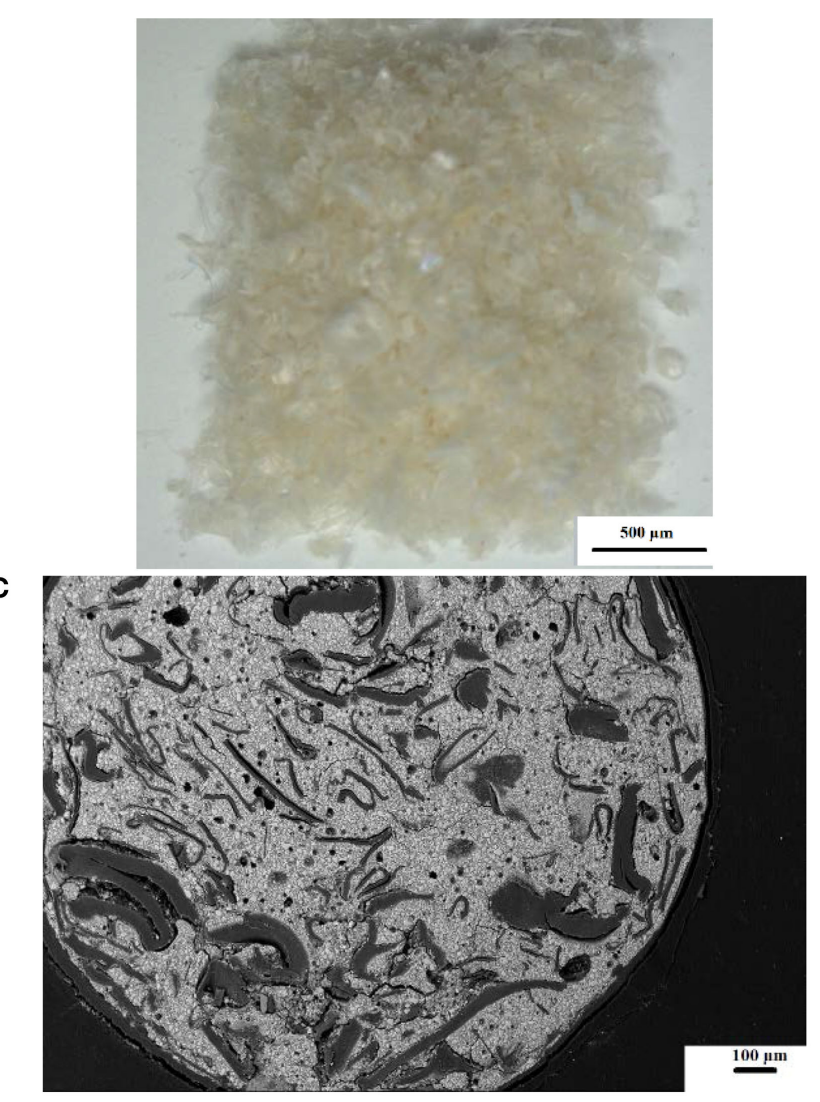

B

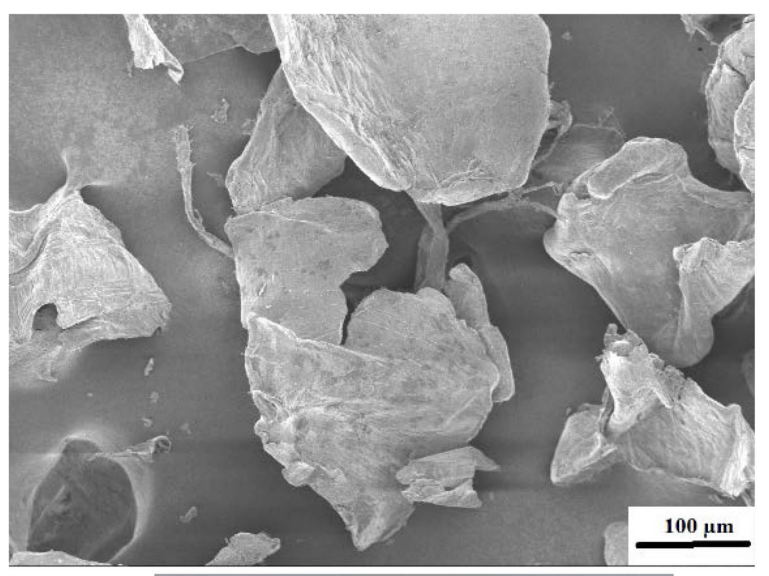

D

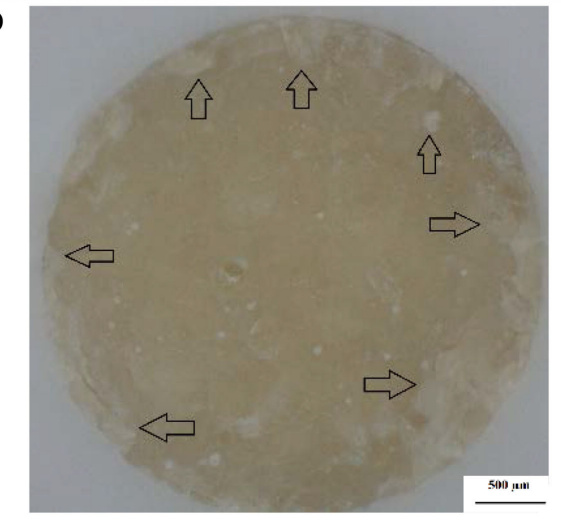

FIGURE 5 | (A) Commercial chitosan particles at 6× magnification; (B) SEM illustrating the irregular shape of commercial chitosan particles; (C) SEM image of KU10\% CH illustrating irregular chitosan particle shape and non-fusion with GIC; (D) chitosan particles clearly visible as whitish flakes (black arrows).

biofilm cover the GICs matrix as well as the filler particles. The $\mathrm{KU} 5 \% \mathrm{CH}$ material modified with chitosan (Figure 8B) and the nanodiamond-agglomerated particles modified into the GIC to form the RSC5\%ND material also showed $S$. mutans adherence (Figure 9B).

The adhesion level of $S$. mutans to the $\mathrm{FN}$ glass ionomer was higher than other regularly used non-GIC dental materials [60]. The presence of $S$. mutans on the GIC surfaces of FN (Figure 2A), KU (Figure 2B) and RSC (Figure 2C) are indicated by the white arrows and the difference in biofilm is visible. The $\mathrm{red} /$ white arrows at the nanodiamond/GIC interface indicate that for FN10\%ND (Figures 10A,B), the nanodiamond agglomerate separated from the GIC matrix. This did not occur during the sample preparation for the SEM investigation since the $S$. mutans can be seen to colonize well within the space between the nanodiamond-agglomerated particle and the GIC surface. S. mutans had therefore been noted to have adherence capabilities and this study confirmed that even in the absence of an initial pioneer pellicle, S. mutans as a mono-species was also able to adhere to all the GICs.

With regard to FN, differences were seen between the surface growth of the biofilm and the $S$. mutans at $24 \mathrm{~h}$ although there was no significant difference in the $S$. mutans OD450 nm at $24 \mathrm{~h}$ between the nanodiamond- and chitosan modifications with their control materials for FN (0.783) (Figure 2A), FN5\%ND (0.759) (Figure 7A), and FN10\%CH (0.831).

The antibacterial effect for the nanodiamonds are derived from the interaction of the amino acids and the proteins from the growth medium with the nanodiamond particles that reduce the toxic effects of the nanodiamond particles. It has been shown that the nanodiamond particles used in this in vitro study (PL-D-G01) exhibit a variety of reactive oxygen groups like acid anhydrides. The acid anhydrides have two acyl groups joined together by an oxygen atom. The other oxygen-containing functional groups such as hydroxyl, alkyl-(derived from sp3carbon), carboxylic- $(\mathrm{C}=\mathrm{O})$ and aromatic groups $(\mathrm{C}=\mathrm{C})[40,43]$ have been noted by other researchers. The various oxygencontaining functional groups add to the antibacterial activities of the nanodiamond particles. The major surface groups of the nanodiamond particles used in this dissertation (PL-DG01) are therefore carboxylic acid $\left(\mathrm{COOH}^{-}\right)$and hydroxide $\left(\mathrm{OH}^{-}\right)$[61]. It has been documented that biological fluids rapidly cover nanoparticles [62]. These terminated carboxyl groups and other oxygen-containing groups of the nanodiamond particles 


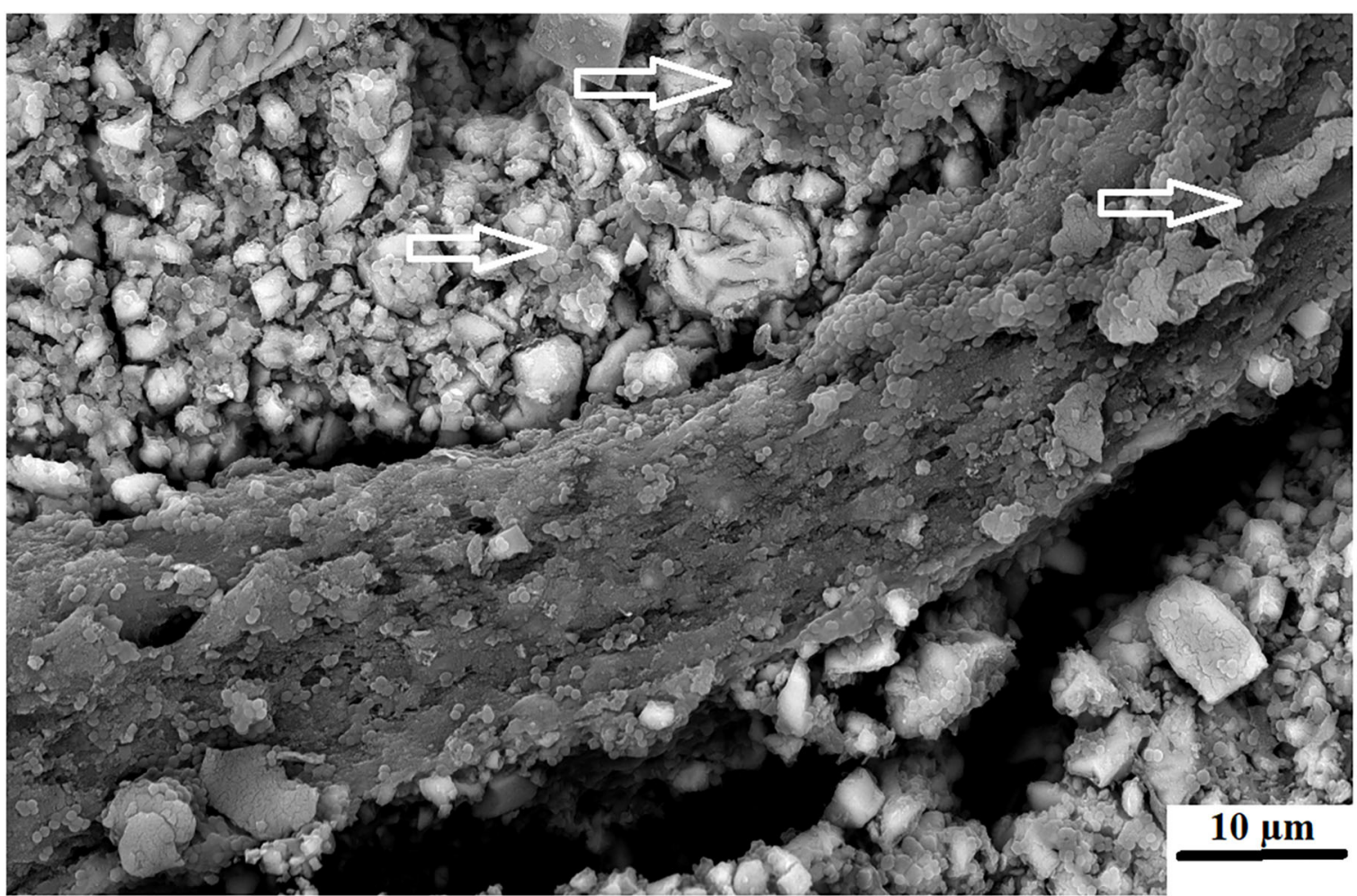

FIGURE 6 | FN5\%CH where the chitosan swelled above GIC surface with S. mutans visible (white arrows).
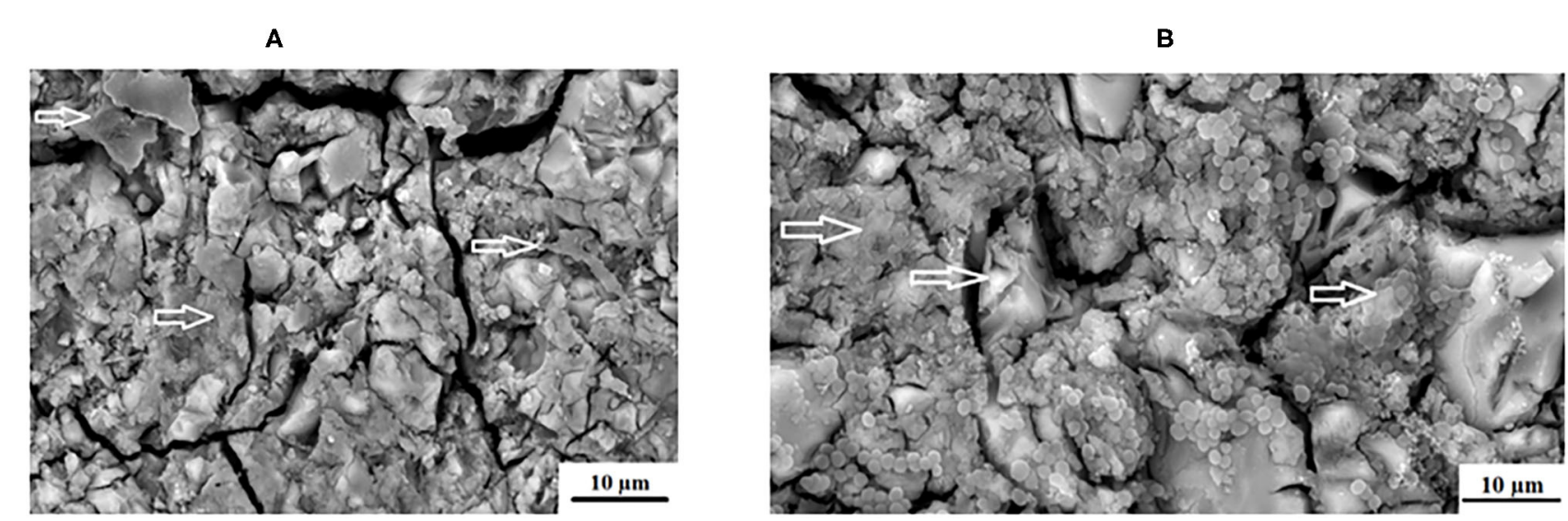

FIGURE 7 | Varied appearance between (A), FN5\%ND and (B), FN10\%CH with the white arrows indicating the S. mutans biofilm.

readily interact with amino groups of proteins [42]. Although the antibacterial effect could potentially be overshadowed by the interaction of the growth medium, the in vivo situation for nanodiamond particles would be similar since its carboxylic acid groups in the acid anhydride form are highly reactive toward nucleophilic additions [63] with the biofilm and cell membrane of all bacteria.

During the increased S. mutans growth over the incubation period, the lactic acid produced by the $S$. mutans interact with the chitosan (Figure 6) that can be readily seen on the surface of the chitosan-modified GICs demonstrating how the chitosan particle has changed when compared to Figures 5A,B. This interaction and the subsequent formation of polyelectrolyte complexes by the chitosan particles [64] provide the required physicochemical properties needed to increase the ion release from the modified GICs causing the chitosan-modified GICs to reduce the S. mutans OD450 nm. 
A

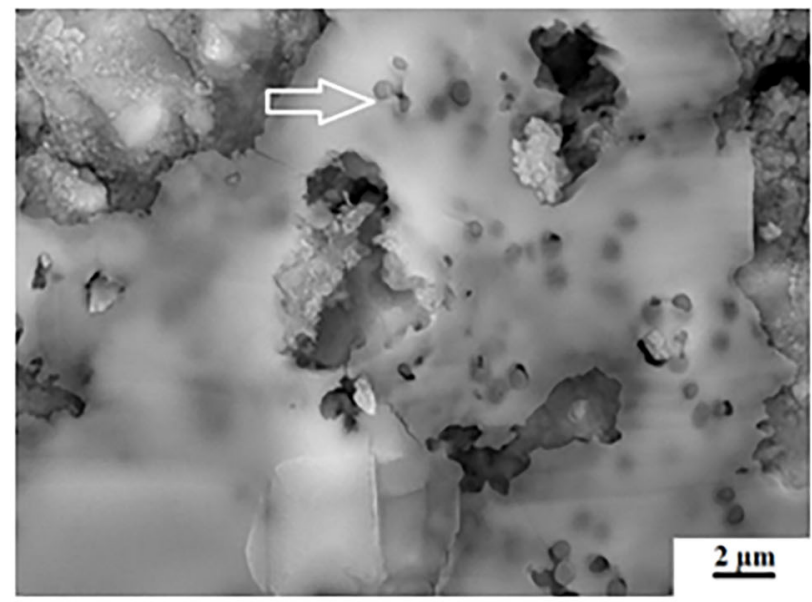

B

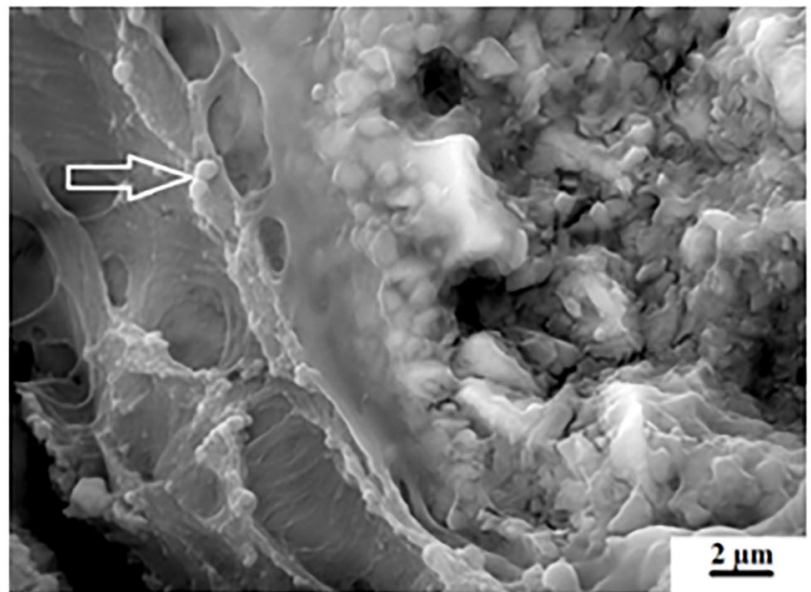

FIGURE 8 | Varied appearance between (A), KU and (B), $\mathrm{KU10} \% \mathrm{CH}$ with the white arrows indicating the S. mutans biofilm.

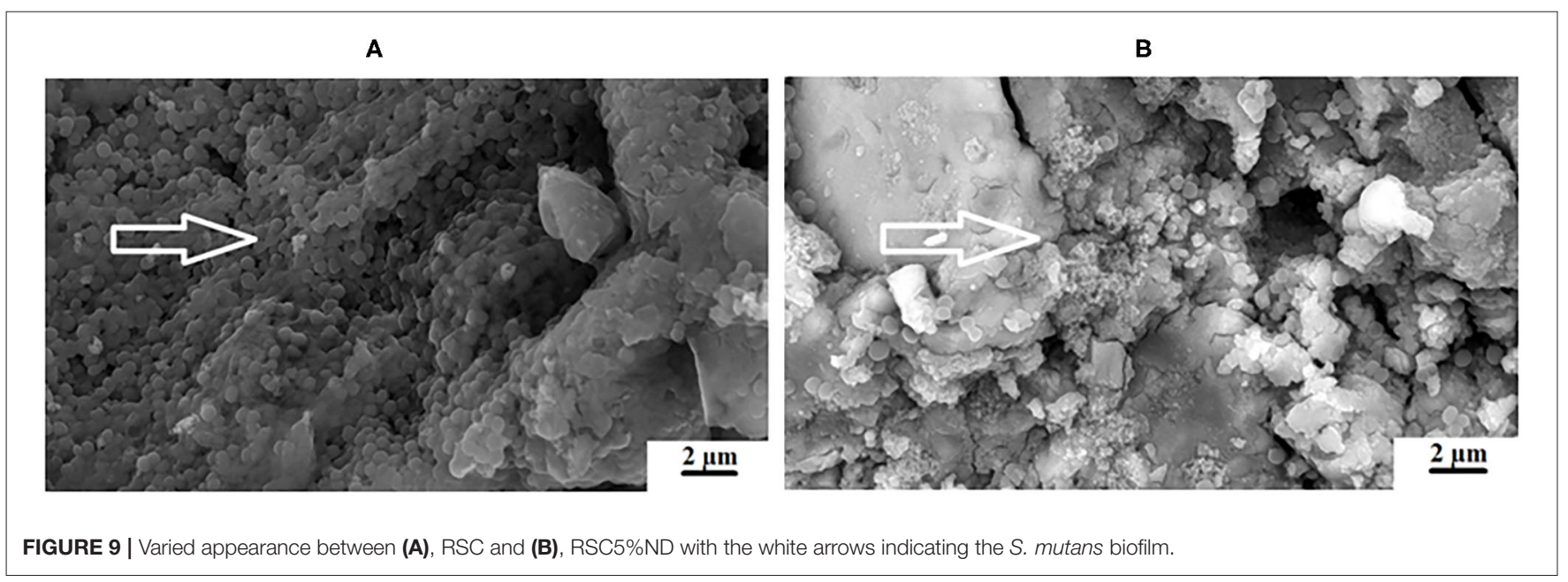

The significant reduction of the S. mutans OD $450 \mathrm{~nm}$ at 2 and $24 \mathrm{~h}$ in relation to the control $S$. mutans was in line with a study completed with dissolved chitosan and $S$. mutans biofilm growth that was continuously assessed over a 24-h period [65].

It has been noted from the research completed [40], indicated that there could be potential interaction with the growth medium for the S. mutans that could inhibit the effects of the chitosan and the nanodiamond particles. Nanodiamond particles have shown to be non-toxic to eukaryotic cells [66]. The non-toxic effect of the nanodiamond particles is due to the affinity of nanodiamond particles to the essential amino acids and proteins. If the nanodiamond particles interact with the essential amino acids and proteins, it would not be able to have a toxic effect on the eukaryotic cells.

This binding of the nanodiamond particles would subsequently inhibit vital enzyme and protein production, decreasing metabolism and resulting in eventual cell death of the bacteria [40]. Due to the negative Zeta potential of the nanodiamond particles, there is usually high dispersion stability in basic aqueous $\mathrm{pH}$ solutions. This feature further indicate the presence of carboxylic groups on the surface of the nanodiamond particles [67]. With the surface chemistry of the nanodiamond particles creating a high affinity for amino acid protein adsorption [68]. The carboxylate groups promote the electrostatic breaking of hydrogen bonds between the water molecules. The interaction of water molecules with the carboxylate group results in fewer water molecules in the double hydrogen bond donor configuration and more in a single hydrogen bond configuration [69]. Increased water sorption and the nanodiamond particle becoming more positive as the water sorption occur, result in an increased antibacterial activity as time passes. This matches well with the 
A

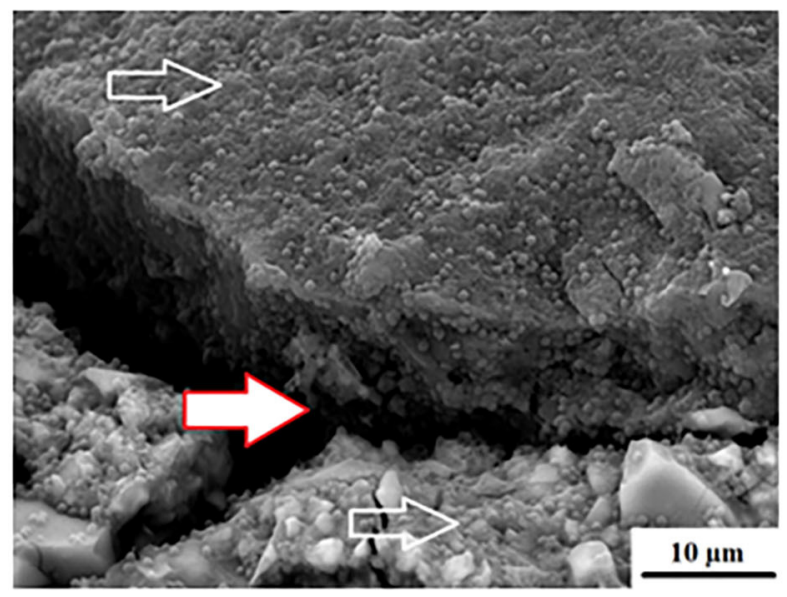

B

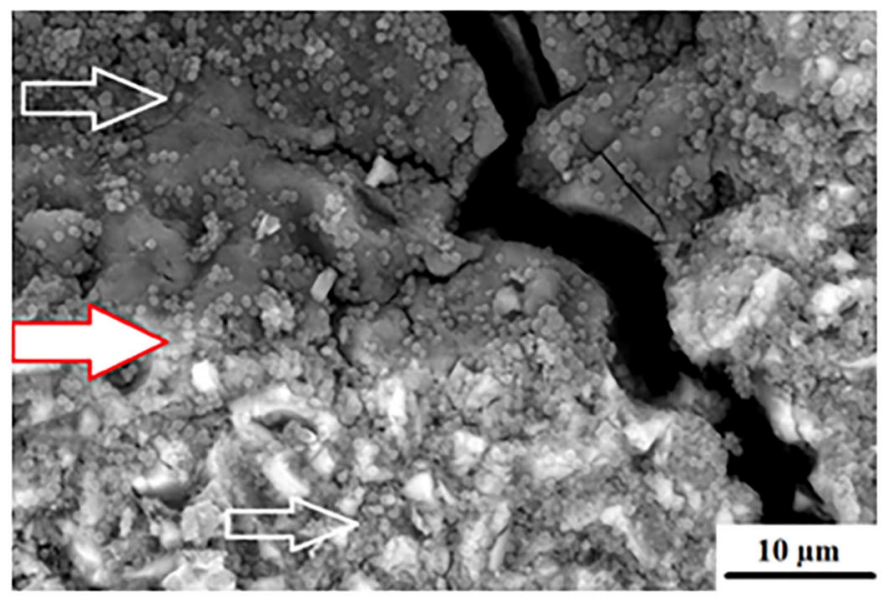

FIGURE 10 | Varied appearance between (A), FN10\%ND and (B), KU10\%ND with the white arrows indicating the S. mutans.

24-h reduction of the $S$. mutans OD $450 \mathrm{~nm}$ compared to the control materials.

The antibacterial effect of chitosan is attributed to its chemical structure, with the presence of deacetylated C2 amino groups which become protonated and positively charged at $\mathrm{pH}<6.5$. Thus, chitosan binds to the membrane of bacterial cells leading to: (1) an increase in membrane permeability with a concomitant increase in the outward flow of ions and proteins from the microbial cell (2) the inhibition of mRNA transcription, and (3) the alteration of protein translation [70, 71]. The molecular weight of chitosan appears to be strongly related to the antibacterial activity of chitosan [72, 73]. The molecular weight may be correlated with the mechanism of destabilization of the bacterial membrane. The lipoteichoic acid that is present in gram-positive bacteria acts as a binding site for chitosan, causing alteration of membrane functionality [74]. In gram-negative bacteria, the chitosan polycations compete with divalent cations and interact with the bacterial cell membrane through electrostatic interactions [75].

The nanodiamond particles provided a greater disruption of the $S$. mutans as illustrated in Figure 9B even though the S. mutans OD $450 \mathrm{~nm}$ was not as low as the chitosan modifications for each material. Nanodiamond particles with the positive influence clearly visible on the nanodiamondmodified GICs surface had reduced surface biofilm compared to the RSC. The biofilm on the nanodiamond-modified GIC is disrupted and not multi-layered. There are also more single $S$. mutans present on the nanodiamondmodified GIC as opposed to a thick multi-cell quorum of S. mutans bacteria.

With the biofilm clearly disrupted in the nanodiamondmodified materials, the $S$. mutans would be more loosely bound. This would therefore provide an opportunity for the removal of the loosely bound $S$. mutans during the daily oral hygiene routines of patients.

\section{CONCLUSIONS}

The presence of the bacterial biofilm on the margins of restorations had been established as a promoter of secondary caries. Based on the SEM images it became clear that the chitosan and nanodiamond modifications disrupted the appearance of the biofilm and the resultant $S$. mutans growth at $24 \mathrm{~h}$. The control materials and their chitosan/nanodiamond modifications showed significant growth at $6 \mathrm{~h}$ compare to the preceding time periods of 2 and $4 \mathrm{~h}$. The materials FN, FN modified with $5 \%$ Nanodiamonds, FN modified with 10\% Chitosan and KU modified with $10 \%$ Chitosan performed the best with regard to the bacterial reduction. Only the chitosan modifications showed an increase in the surface roughness after $24 \mathrm{~h}$ of exposure to the $S$. mutans. The chitosan and the nanodiamond modifications provided the best disruption of the S. mutans biofilm formation.

\section{Limitations and Future Recommendations}

There was no positive control (e.g., composite, compomer, giomer, or ceramic), nor a negative control (enamel or dentine). The effect of the S. mutans and the formation of the biofilm would have added value to the growth and biofilm formation of the S. mutans on these substrates to elaborate how it differs from GICs and the modifications. Additional species (e.g., Streptococcus Salivarious, Lactobacilli, Actinomyces) could be added in future studies to provide a more complex biofilm on the materials. This more complex biofilm will alter the bacterial film and assess the release of lactic acid for the change in surface roughness of the materials with linear regression analysis. The adhesion of the biofilms could be 
investigated to provide insight to the direct contact to the restorative materials.

Further research with nanodiamond particles should focus on the incorporation of the nanodiamond particle is in the liquid form to assess if they achieve a greater wetting by the liquid of the GICs. Further this could possibly reduce or eliminate the agglomerated particles completely.

\section{DATA AVAILABILITY STATEMENT}

The raw data supporting the conclusions of this article will be made available by the authors, without undue reservation.

\section{REFERENCES}

1. van Houte J, Gibbs G, Butera C. Oral flora of children with "nursing bottle caries." J Dent Res. (1982) 61:382-5. doi: 10.1177/00220345820610020201

2. Kawamura Y, Hou X, Sultana F, Miura H, Ezaki T. Determination of $16 \mathrm{~S}$ rRNA sequences of Streptococcus mitis and Streptococcus gordonii and phylogenetic relationships among members of the genus Streptococcus. Int J Syst Bacteriol. (1995) 45:882-882. doi: 10.1099/00207713-45-4-882a

3. Banas J. Virulence properties of Streptococcus mutans. Front Biosci. (2004) 9:1267. doi: 10.2741/1305

4. Kuramitsu H, Wang B. Virulence properties of cariogenic bacteria. BMC Oral Health. (2006) 6:S1. doi: 10.1186/1472-6831-6-s1-s11

5. Carlsson P, Olsson B, Bratthall D. The relationship between the bacterium Streptococcus mutans in the saliva and dental caries in children in Mozambique. Arch Oral Biol. (1985) 30:265-8. doi: 10.1016/0003-9969(85)90043-3

6. Loeshe W. Role of Streptococcus mutans in human dental decay. Microbiol Rev. (1986) 50:353-80.

7. Ajdic D, McShan W, McLaughlin R, Savic G, Chang J, Carson M, et al. Genome sequence of Streptococcus mutans UA159, a cariogenic dental pathogen. Proc Natl Acad Sci. (2002) 99:14434-9. doi: 10.1073/pnas.172501299

8. Welin-Neilands J, Svensater G. Acid tolerance of biofilm cells of Streptococcus mutans. Appl Environ Microbiol. (2007) 73:56338. doi: 10.1128/aem.01049-07

9. Hamada S, Slade H. Biology, immunology, and cariogenicity of Streptococcus mutans. Microbiol Mol Biol Rev. (1980) 44:331-84.

10. Khoo G, Hoover C, Featherstone J. Cariogenic virulence characteristics of mutans streptococci isolated from caries-active and caries-free adults. J Calif Dent Assoc. (2005) 33:973-80.

11. Geddes D. The production of $\mathrm{L}(+)$ and $\mathrm{D}(-)$ lactic acid and volatile acids by human dental plaque and the effect of plaque buffering and acidic strength on pH. Arch Oral Biol. (1972) 17:537-45. doi: 10.1016/0003-9969(72) 90069-6

12. Palenik C, Behnen M, Setcos J, Miller C. Inhibition of microbial adherence and growth by various glass ionomers in vitro. Dent Mater. (1992) 8:1620. doi: 10.1016/0109-5641(92)90047-g

13. Nakajo K, Imazato S, Takahashi Y, Kiba W, Ebisu S, Takahashi N. Fluoride released from glass-ionomer cement is responsible to inhibit the acid production of caries-related oral streptococci. Dent Mater. (2009) 25:7038. doi: 10.1016/j.dental.2008.10.014

14. Wiegand A, Buchalla W, Attin T. Review on fluoride-releasing restorative materials: fluoride release and uptake characteristics, antibacterial activity and influence on caries formation. Dent Mater. (2007) 23:343-62. doi: 10.1016/j.dental.2006. 01.022

15. Dimkov A, Nicholson J, Gjorgievska E. Compressive strength and setting time determination of glass-ionomer cements incorporated with cetylypyridinium chloride and benzalkonium chloride. Contrib Sec Biol Med Sci Macedonian Acad Sci Arts. (2012) 33:243-63.

\section{AUTHOR CONTRIBUTIONS}

RM and EM: conceptualization and methodology. RM: investigation and data curation. EM: resources, supervision, and project administration. RA and RM: writing-original draft preparation and writing-review and editing. All authors have read and agreed to the published version of the manuscript.

\section{FUNDING}

Article processing charges financed by the author fund of RM, with funding number: MUL111388.

16. Botelho M. Inhibitory effects on selected oral bacteria of antibacterial agents incorporated in a glass ionomer cement. Caries Res. (2003) 37:10814. doi: $10.1159 / 000069019$

17. Ribeiro J, Ericson D. In vitro antibacterial effect of chlorhexidine added to glass-ionomer cements. Eur J Oral Sci. (1991) 99:53340. doi: 10.1111/j.1600-0722.1991.tb01066.x

18. Osinaga P, Grande R, Ballester R, Simionato M, Delgado Rodrigues C, Muench A. Zinc sulfate addition to glass-ionomer-based cements: influence on physical and antibacterial properties, zinc and fluoride release. Dent Mater. (2003) 19:212-7. doi: 10.1016/s0109-5641(02)00032-5

19. Mabrouk M, Selim M, Beherei H. Incorporation effect of silver and zinc zeolites into commercial glass ionomer cements. Interceram. (2013) 62:50-4. doi: 10.1080/23337931.2018.1539623

20. Ching H, Luddin N, Kannan T, Ab Rahman I, Abdul Ghani N. Modification of glass ionomer cements on their physical-mechanical and antimicrobial properties. J Esthet Restor Dent. (2018) 30:557-71. doi: 10.1111/jerd.12413

21. Debnath A. Comparative evaluation of antibacterial and adhesive properties of chitosan modified glass ionomer cement and conventional glass ionomer cement: an in vitro study. J Clin Diag Res. (2017) 11:ZC758. doi: $10.7860 /$ jcdr/2017/25927.9593

22. Ibrahim M, Neo J, Esguerra R, Fawzy A. Characterization of antibacterial and adhesion properties of chitosan-modified glass ionomer cement. J Biomater Appl. (2015) 30:409-19. doi: 10.1177/0885328215589672

23. Ibrahim M, Meera PB, Neo J, Fawzy A. Characterization of chitosan/ $/ \mathrm{TiO}_{2}$ nano-powder modified glass-ionomer cement for restorative dental applications. J Esthet Restor Dent. (2017) 29:146-56. doi: 10.1111/jerd.12282

24. Bollen C, Lambrechts P, Quirynen M. Comparison of surface roughness of oral hard materials to the threshold surface roughness for bacterial plaque retention: a review of the literature. Dent Mater. (2017) 13:25869. doi: 10.1016/s0109-5641(97)80038-3

25. Auschill T, Arweiler N, Brecx M, Reich E, Sculean A, Netuschil L. The effect of dental restorative materials on dental biofilm. Eur J Oral Sci. (2002) 110:48-53. doi: 10.1046/j.0909-8836.2001.101160.x

26. Danilenko V. On the history of the discovery of nanodiamond synthesis. Phys Solid State. (2004) 46:595-9. doi: 10.1134/1.1711431

27. Carlén A, Nikdel K, Wennerberg A, Holmberg K, Olsson J. Surface characteristics and in vitro biofilm formation on glass ionomer and composite resin. Biomater. (2001) 22:481-7. doi: 10.1016/s0142-9612(00)00204-0

28. Ma Y, Marquis R. Thermophysiology of Streptococcus mutans and related lactic-acid bacteria. Antonie Van Leeuwenhoek. (1997) 72:91100. doi: 10.1023/a:1000290426248

29. Ullah M, Kausar A, Siddiq M, Subhan M, Abid Zia M. Reinforcing effects of modified nanodiamonds on the physical properties of polymerbased nanocomposites: a review. Polym Plast Technol Eng. (2015) 54:86179. doi: 10.1080/03602559.2014.979505

30. Panich A, Altman A, Shames A, Osipov V, Aleksenskiy A, Vul' A. Proton magnetic resonance study of diamond nanoparticles decorated by transition metal ions. J Phys D Appl Phys. (2011) 44:125303. doi: 10.1088/0022-3727/44/12/125303 
31. Scannapieco F. Saliva-bacterium interactions in oral microbial ecology. Crit Rev Oral Biol Med. (1994) 5:203-48. doi: 10.1177/10454411940050030201

32. Bollen C, Papaioanno W, Van Eldere J, Schepers E, Quirynen M, van Steenberghe D. The influence of abutment surface roughness on plaque accumulation and peri-implant mucositis. Clin Oral Implants Res. (1996) 7:201-11. doi: 10.1034/j.1600-0501.1996.070302.x

33. Fejerskov O, Kidd E. Etiologia e epidemiologia da Cárie Dentária. A doença e seu tratamento clínico. (2005). p. 350-53. Available online at: https:// www.unasus.unifesp.br/biblioteca_virtual/esf/3/unidades_casos_complexos/ unidade27/unidade27_ft_etiologia.pdf (accessed July 22, 2020).

34. Hayacibara M, Rosa O, Koo H, Torres S, Costa B, Cury J. Effects of fluoride and aluminum from ionomeric materials on S. mutans. Biofilm J Dent Res. (2003) 82:267-71. doi: 10.1177/154405910308200405

35. Banas J, Vickerman M. Glucan-binding proteins of the oral streptococci. Crit Rev Oral Biol Med. (2003) 14:89-99. doi: 10.1177/1544111303014 00203

36. Yamashita Y, Bowen W, Burne R, Kuramitsu H. Role of the Streptococcus mutans gtf genes in caries induction in the specific pathogen free rat model. Infect Immun. (1993) 61:3811-7.

37. Schilling K, Bowen W. Glucans synthesized in situ in experimental salivary pellicle function as specific binding sites for Streptococcus mutans. Infect Immun. (1992) 60:284-95.

38. Hannig M. Transmission electron microscopic study of in vivo pellicle formation on dental restorative materials. Eur J Oral Sci. (1997) 105:42233. doi: 10.1111/j.1600-0722.1997.tb02139.x

39. Da Silva R, Zuanon A, Spolidorio D, Campos J. Antibacterial activity of four glass ionomer cements used in atraumatic restorative treatment. J Mater Sci Mater Med. (2007) 18:1859-62. doi: 10.1007/s10856-007-3035-4

40. Wehling J, Dringen R, Zare R, Maas M, Rezwan K. Bactericidal activity of partially oxidized nanodiamonds. ACS Nano. (2014) 8:647583. doi: $10.1021 / \mathrm{nn} 502230 \mathrm{~m}$

41. Chng E, Pumera M. The toxicity of graphene oxides: dependence on the oxidative methods used. Chem Eur J. (2013) 19:822735. doi: 10.1002/chem.201300824

42. Huang L, Chang H. Adsorption and immobilization of cytochromecon nanodiamonds. Langmuir. (2004) 20:5879-84. doi: 10.1021/la0495736

43. Mochalin V, Shenderova O, Ho D, Gogotsi Y. The properties and applications of nanodiamonds. Nat Nanotechnol. (2011) 7:11-23. doi: 10.1038/nnano.2011.209

44. Bika D, Gentzler M, Michaels J. Mechanical properties of agglomerates. Powder Technol. (2001) 117:98-112. doi: 10.1016/s0032-5910(01)00318-7

45. Nyvad B, Fejerskov O. Scanning electron microscopy of early microbial colonization of human enamel and root surfaces in vivo. Eur J Oral Sci. (1987) 95:287-96. doi: 10.1111/j.1600-0722.1987.tb01844.x

46. Yip K, Lam W, Smales R. Fluoride release, weight loss and erosive wear of modern aesthetic restoratives. Br Dent J. (1999) 187:26570. doi: 10.1038/sj.bdj.4800256a

47. Yip H, Peng D, Smales R. Effects of APF gel on the physical structure of compomers and glass ionomer cements. Oper Dent. (2001) 26:231-8. Available online at: https://europepmc.org/article/med/11357564

48. Bala O, Arisu H, Yikilgan I, Arslan S, Gullu A. Evaluation of surface roughness and hardness of different glass ionomer cements. Eur J Dent. (2012) 6:79-86.

49. Wallman C, Krasse B. Mutans streptococci in margins of fillings and crowns. J Dent. (1992) 20:163-6. doi: 10.1016/0300-5712(92)90130-5

50. Sonia T, Sharma C. Chitosan for biomaterials I. Adv Polym Sci. (2011) 243:23-54. doi: 10.1007/12_2011_117

51. Yang S, Guo Z, Miao F, Xue Q, Qin S. The hydroxyl radical scavenging activity of chitosan, hyaluronan, starch and their O-carboxymethylated derivatives. Carbohydr Polym. (2010) 82:1043-5. doi: 10.1016/j.carbpol.2010.06.014

52. Guo Z, Xing R, Liu S, Yu H, Wang P, Li C, et al. The synthesis and antioxidant activity of the Schiff bases of chitosan and carboxymethyl chitosan. Bioorg Med Chem Lett. (2005) 15:4600-3. doi: 10.1016/j.bmcl.2005.06.095

53. Halliwell B, Gutteridge J. Role of free radicals and catalytic metal ions in human disease: an overview. Methods Enzymol. (1990) 186:185. doi: 10.1016/0076-6879(90)86093-b

54. Goy R, Britto D, Assis O. A review of the antimicrobial activity of chitosan. Polímeros. (2009) 19:241-7. doi: 10.1590/s0104-14282009000300013
55. Fernandes J, Eaton P, Gomes A, Pintado M, Xavier Malcata F. Study of the antibacterial effects of chitosans on Bacillus cereus (and its spores) by atomic force microscopy imaging and nanoindentation. Ultramicroscopy. (2009) 109:854-60. doi: 10.1016/j.ultramic.2009.03.015

56. Costa E, Silva S, Tavaria F, Pintado M. Study of the effects of chitosan upon Streptococcus mutans adherence and biofilm formation. Anaerobe. (2013) 20:27-31. doi: 10.1016/j.anaerobe.2013.02.002

57. Eick S, Glockmann E, Brandl B, Pfister W. Adherence of Streptococcus mutans to various restorative materials in a continuous flow system. J Oral Rehabil. (2004) 31:278-85. doi: 10.1046/j.0305-182x.2003. 01233.x

58. Seppä L, Torppa-Saarinen E, Luoma H. Effect of different glass lonomers on the acid production and electrolyte metabolism of Streptococcus mutans ingbritt. Caries Res. (1992) 26:434-8. doi: 10.1159/0002 61483

59. Montanaro L, Campoccia D, Rizzi S, Donati M, Breschi L, Prati C, et al. Evaluation of bacterial adhesion of Streptococcus mutans on dental restorative materials. Biomater. (2004) 25:445763. doi: 10.1016/j.biomaterials.2003.11.031

60. Poggio C, Arciola C, Rosti F, Scribante A, Saino E, Visai L. Adhesion of Streptococcus mutans to different restorative materials. Int J Artif Organs. (2009) 32:671-7. doi: 10.1177/039139880903200917

61. Yoshida Y, Van Meerbeek B, Nakayama Y, Snauwaert J, Hellemans L, Lambrechts P, et al. Evidence of chemical bonding at biomaterial-hard tissue interfaces. J Dent Res. (2000) 79:709-14. doi: 10.1177/00220345000790020301

62. Monopoli M, Åberg C, Salvati A, Dawson K. Biomolecular coronas provide the biological identity of nanosized materials. Nat Nanotechnol. (2012) 7:77986. doi: 10.1038/nnano.2012.207

63. Cloete W, Verwey L, Klumperman B. Permanently antimicrobial waterborne coatings based on the dual role of modified poly(styrene-co-maleic anhydride). Eur Polym J. (2013) 49:10808. doi: 10.1016/j.eurpolymj.2013.01.012

64. Berger J, Reist M, Mayer J, Felt O, Gurny R. Structure and interactions in chitosan hydrogels formed by complexation or aggregation for biomedical applications. Eur J Pharm Biopharm. (2004) 57:35-52. doi: 10.1016/s0939-6411(03)00160-7

65. Pasquantonio G, Greco C, Prenna M, Ripa C, Vitali L, Petrelli D, et al. Antibacterial activity and anti-biofilm effect of chitosan against strains of Streptococcus mutans isolated in dental plaque. Int J Immunopathol Pharmacol. (2008) 21:993-7. doi: 10.1177/039463200802100424

66. Xing Y, Dai L. Nanodiamonds for nanomedicine. Nanomedicine. (2009) 4:207-18. doi: 10.2217/17435889.4.2.207

67. Osswald S, Yushin G, Mochalin V, Kucheyev S, Gogotsi Y. Control of sp2/sp3 carbon ratio and surface chemistry of nanodiamond powders by selective oxidation in air. J Am Chem Soc. (2006) 128:11635-42. doi: 10.1021/ja063303n

68. Wang H, Niu C, Yang Q, Badea I. Study on protein conformation and adsorption behaviors in nanodiamond particle-protein complexes. Nanotechnology. (2011) 22:145703. doi: 10.1088/0957-4484/22/14/145703

69. Petit T, Yuzawa H, Nagasaka M, Yamanoi R, Osawa E, Kosugi N, et al. Probing interfacial water on nanodiamonds in colloidal dispersion. J Phys Chem Lett. (2015) 6:2909-12. doi: 10.1021/acs.jpclett.5b00820

70. Adams L, Lyon D, Alvarez P. Comparative eco-toxicity of nanoscale $\mathrm{TiO}_{2}, \mathrm{SiO}_{2}$, and $\mathrm{ZnO}$ water suspensions. Water Res. (2006) 40:352732. doi: 10.1016/j.watres.2006.08.004

71. Blecher K, Nasir A, Friedman A. The growing role of nanotechnology in combating infectious disease. Virulence. (2011) 2:395-401. doi: 10.4161/viru.2.5.17035

72. Huh A, Kwon Y. "Nanoantibiotics": a new paradigm for treating infectious diseases using nanomaterials in the antibiotics resistant era. J Control Release. (2011) 156:128-45. doi: 10.1016/j.jconrel.2011.07.002

73. Fernandes J. In vitro screening for antimicrobial activity of chitosans and chitooligosaccharides, aiming at potential uses in functional textiles. J Microbiol Biotechnol. (2010) 20:311-8. doi: 10.4014/jmb. 0904.04038

74. Raafat $\mathrm{D}$, von Bargen $\mathrm{K}$, Haas $\mathrm{A}$, Sahl H. Insights into the mode of action of chitosan as an antibacterial compound. Appl Environ Microbiol. (2008) 74:3764-73. doi: 10.1128/aem.00453-08 
75. Kong M, Chen X, Liu C, Liu C, Meng X, Yu L. Antibacterial mechanism of chitosan microspheres in a solid dispersing system against E. coli. Colloids Surface B. (2008) 65:197-202. doi: 10.1016/j.colsurfb.2008.04.003

Conflict of Interest: The authors declare that the research was conducted in the absence of any commercial or financial relationships that could be construed as a potential conflict of interest.
Copyright (c) 2020 Mulder, Maboza and Ahmed. This is an open-access article distributed under the terms of the Creative Commons Attribution License (CC BY). The use, distribution or reproduction in other forums is permitted, provided the original author(s) and the copyright owner(s) are credited and that the original publication in this journal is cited, in accordance with accepted academic practice. No use, distribution or reproduction is permitted which does not comply with these terms. 